\title{
Risk behaviors associated with adolescent pregnancy: contemporary challenges related to the substance use
}

\author{
Comportamentos de risco associados à gravidez na adolescência: desafios \\ contemporâneos relacionados ao uso de substâncias
}

Cíntia da Silva Telles Nichele ${ }^{1}$ (D) Aldo Pacheco Ferreira ${ }^{2}$ (D),

\begin{abstract}
:
Adolescent pregnancy is a worldwide public health problem. The number of this phenomenon is increasing every year. One of the reasons for this worsening is the use of substances. This research aimed to discuss adolescent pregnancy due to chemical health risks by inadequate conduct. The method applied consisted of a cross-sectional, observational design study associated with a survey on knowledge, attitudes, and practices, carried out in 42 pregnant adolescents aged 12-18 years in a large public maternity hospital in Rio de Janeiro. A structured questionnaire was applied at their prenatal visit from November 2017 to October 2018. Descriptive tables were prepared using frequencies in absolute numbers and percentages. 11 pregnant adolescents (26.19\%) reported smoking 7 cigarettes per day $(S D=4.51)$, ranging from 5 to 45 cigarettes/day. Concerning alcohol intake, 16 adolescents (38.09\%) admitted to drinking at least one occasion during pregnancy, and $8(19.05 \%)$ in abusive form. Regarding other types of drugs (marijuana, cocaine, crack), 12 (28.57\%) admitted to having used them during pregnancy, and 3 $(7.14 \%)$ of these reported injecting drug use. 7 adolescents $(16.66 \%)$ had a relationship with an injecting drug user partner. The survey results show that the use of illicit drugs by the pregnant adolescents interviewed was 4 times higher than the prevalence recorded in the literature for people aged 12 to 17 years. In the case of cigarette use, this difference was also observed, reaching 20 percentage points.
\end{abstract}

KEYWORDS: Substance use, Occurrence, Chemical health risk, Prevention.

\section{RESUMO:}

A gravidez na adolescência é um problema de saúde pública mundial. O número desse fenômeno está aumentando a cada ano. Uma das razões para esse agravamento é o uso de substâncias. Esta pesquisa teve como objetivo discutir a gravidez na adolescência e o risco químico à saúde de comportamentos inadequados. O método aplicado consistiu em um estudo transversal de desenho observacional associado ao levantamento de conhecimentos, atitudes e práticas realizado em 42 adolescentes grávidas de 12 a 18 anos em uma maternidade pública de grande porte no Rio de Janeiro. Foi aplicado questionário estruturado na consulta pré-natal de novembro de 2017 a outubro de 2018. Foram elaboradas tabelas descritivas com frequências em números absolutos e percentuais. 11 adolescentes $(26,19 \%)$ relataram ter fumado 7 cigarros por dia (DP $=4,51)$, com variação de 5 a 45 cigarros / dia. Em relação ao consumo de álcool, $16(38,09 \%)$ admitiram ter bebido pelo menos uma vez durante a gravidez e $8(19,05 \%)$ de forma abusiva. Em relação aos outros tipos de drogas, $12(28,57 \%)$ admitiram ter consumido durante a gravidez e $3(7,14 \%)$ delas relataram uso de drogas intravenosas. $7(16,66 \%)$ relacionavam-se com outro usuário de drogas injetáveis. Os resultados da pesquisa mostram que o uso de drogas ilícitas pelas adolescentes grávidas entrevistadas foi 4 vezes maior do que a prevalência registrada na literatura para pessoas de 12 a 17 anos. No caso do uso de cigarro, essa diferença também foi observada, chegando a 20 pontos percentuais.

Palavras-Chave: Uso de substâncias, Ocorrência, Risco químico para a saúde, Prevenção.

\footnotetext{
Fundação Oswaldo Cruz (Fiocruz), Escola Nacional de Saúde Pública Sergio Arouca (Ensp). Programa de Pós-graduação em Saúde Pública - Rio de Janeiro (RJ), Brasil

2 Fundação Oswaldo Cruz (Fiocruz), Escola Nacional de Saúde Pública Sergio Arouca (Ensp). Departamento de Direitos Humanos, Saúde e Diversidade Cultural - Rio de Janeiro (RJ), Brasil
} 


\section{INTRODUCTION}

Substance abuse by adolescents is alarming in our society and a variety of reasons may be involved: peer pressure, social acceptance, psychological problems, and family history are the most common reasons noted $[1,2]$. Fitting in and being part of the group without feeling self-conscious are important to teens, who seek acceptance. Osaki et al. [3] identify three motives that lead to drug use: The first motive is to expand awareness or heighten sensitivity and insight. A second motive is to seek thrills and to experience new things with peers. The last motive is simply to get high, to feel the drug's effect. The effect of the drug causes adolescents to be less inhibited and may lead them to unsafe sexual practices.

The adolescent context is a critical period in the biopsychosocial development of the individual characterized by an accentuation in the biological maturation process associated with building aspects of identity, self-concept, self-esteem, character and various factors involved in social relations, where experimental drug use is often initiated and may evolve into compulsive and harmful use $[4,5]$.

Consequently, adolescent pregnancy has been a worldwide issue and has raised many campaigns and awareness to lessen its occurrence, especially in third world countries [6]. The total number of this phenomenon is increasing each year [5]. It should be noted that adolescence is a period of vulnerability for substance use and substance use disorders; some adolescents start engaging in substance use earlier than their peers, and early substance use is associated with a higher risk of adult dependence [7].

Research on adolescent substance use and sexual risk behavior suggests that substance use and teen pregnancy are entangled [8-10]. Epidemiological studies have also documented the comorbidity of health-risk behaviors, including substance use and sexual behaviors that place youth at risk for early pregnancy $[11,12]$. Moreover, the overlap of etiology and comorbidity, important evidence indicates an instrumental role of substance use by adolescents in sexual behaviors that put youth at risk for early pregnancy [1315]. For instance, research suggests that many adolescents use licit and illicit substances before intercourse and facilitate sexual encounters [16]. This is noteworthy as intercourse under the influence of alcohol or drugs is associated with decreased condom use, particularly when the intercourse is unplanned 17].

Such discoveries converge with investigational studies demonstrating the disinhibiting effects and impaired cognitive functioning of alcohol and other substances [16], all of which are associated with increased risk for involvement in sexual risk behavior $[18,19]$. Evidence also suggests that substance use can contribute to the increased likelihood of sexual risk behavior by exposing youth to peer groups ratifying more compassionate sexual norms $[20,21]$. In the same way, other authors have suggested that drug use is associated with an early adoption of adult roles, and its use impairs the normal progression and completion of adolescent developmental tasks [15]. This premature or pseudo-maturity may be especially evident in girls who become pregnant as adolescents, many of whom take on the role of parent at a very young age [22].

Smoking is prevalent among pregnant adolescents [23], and both tobacco and marijuana use are common among them and adult women who gave birth during adolescence [24]. Adolescent motherhood is also associated with adverse outcomes that may contribute to the continuity of problem behaviors into adulthood [25]. For example, pregnant adolescents are more likely to experience low socioeconomic status and suffer from more mental health problems as adults [12]. These circumstances may explain some or all the effects of early motherhood on persistent substance use. Furthermore, racial/ethnic differences between women who give birth as adolescents and other young women may also promote differences in their adult patterns of substance use [26].

Pregnant substance abuse is a critical problem, and adolescent mothers appear to be at high risk for such behaviors $[2,27,28]$. For instance, pregnant adolescents who are substance abusers are at higher risk of pregnancy complications and place their fetuses at increased risk of low birth weight, prematurity, decreased head circumference, developmental delay, sud- 
den infant death syndrome, and drug withdrawal complications [13]. Substances such as amphetamines, cocaine, and nicotine can be transferred together with carriers of nutrients, which reduces the delivery of nutrients to the fetus and contributes to the health deficit [29]. The question of just what the relationship between early pregnancy and substance use among adolescents remains unanswered. From a public health perspective, both behaviors are unwanted, and populations that are at risk are often at high risk for both.

Substance use in pregnant adolescents is a great public health problem: not only are these young women shortening and reducing the quality of their own lives, but they are also placing multiple children at risk of prenatal exposure. Additionally, emphasize the corresponding etiology of substance use with involvement in sexual risk behaviors, such as unprotected sexual intercourse, that place youth at risk for early pregnancy $[1,30]$. In light of this, the question arises: are there behaviors related to greater exposure of adolescents to early pregnancy? What would they be? Thus, this research aimed to discuss the risk behaviors engaged in adolescent pregnancy.

\section{MATERIALS AND METHODS}

\section{Participants}

This study had a cross-sectional, observational design study associated with knowledge, attitudes, and practices. The study included pregnant adolescents, considered those aged 12 to 18 years admitted at the Hospital for their prenatal. The survey was carried out in 42 pregnant adolescents aged $12-18$ years accomplished from November 2017 to October 2018. Inclusion occurred after obtaining written informed consent. No exclusion criteria were used.

\section{Data collection}

The data collection took place at Alexander Fleming Maternity Hospital, which is in a large public maternity hospital located in the city of Rio de Janeiro, in the North Zone of the city of Rio de Janeiro, and is considered a tertiary level hospital. This Maternity Hospital has a large obstetric center, with twelve pre-delivery beds, and serves more than 5,000 births annually, resulting from low and high-risk pregnancies, and among these specialties include pregnant adolescents.

\section{Procedures}

Participants were interviewed in a private room at the hospital by independent interviewers, with no link to maternity. They were trained professionals with previous research experience, with a specific performance for this task. The data collection instrument used was a structured form specifically designed for this study. The variables related to data were considered: Identification: age, origin, and neighborhood of residence, marital status; Social inclusion: education and professional situation; Socio-economic level: household income; livelihood; Pregnancy: planning; reference of having performed prenatal care or not; About the child's father and other children; About sex life: the beginning of sexual activity; information on the number of sexual partners you had; stability of the relationship that led to pregnancy; knowledge about sexually transmitted diseases and condom use during sex; About situations of violence to which it has already been subjected; About the use of licit or illicit drugs during pregnancy.

\section{Ethical aspects}

The project received approval from the Ethics Committee on Research with Human Beings, respecting the ethical principles according to Resolution CNS 510/2016.

\section{Statistical analyses}

The database was constituted by the Epi Info program, version 7.2 (Centers for Disease Control and Prevention, Atlanta, United States). For data analysis, the SPSS package 22.0 (SPSS Inc., Chicago, United States) was used. Descriptive tables were prepared using frequencies in $a b-$ solute numbers and percentages. 


\section{RESULTS}

The average age of the participants was 14.6 years $(S D=3.75)$, ranging from 12 to 18 years; $47.62 \%$ were up to 16 years old $(n=20)$. The vast majority (76.19\%) were from Rio de Janeiro $(n=32)$ and the rest were in the city for 6.9 years on average $(S D=5.5)$, ranging from 1 to 18 years. Most $(71.43 \%)$ of the adolescents $(n=30)$ lived in neighborhoods adjacent to the hospital. Regarding family structure, only $7.14 \%$ were legally married $(n=3)$, but $61.9 \%$ reported living with a partner $(n=26)$. In the total, $40.48 \%$ lived exclusively with their partner and/or children constituting an independent family nucleus $(n=17)$, while the others $(57.14 \% ; n=24)$ continued to live with other relatives, $(14.28 \% ; n=6)$ with other children, $(42.86 \% ; n=18)$ with mother, $(26.19 \%$; $\mathrm{n}=11)$ with parents, $(45.24 \% ; \mathrm{n}=19)$ with siblings. An average of three people lived in the same house; in $21.43 \%(n=9)$ of cases, more than five people (Table 1 ).

Table 1. Demographic, socioeconomic and lifestyle characteristics of pregnant adolescents, Rio de Janeiro, 2017-2018

\begin{tabular}{llcc}
\hline \multirow{2}{*}{ Characteristics } & & Pregnant adolescents (n=42) \\
\cline { 2 - 3 } Skin color & & $\mathbf{n}$ & \% \\
Marital status & white & 13 & 30.96 \\
& Non-white & 29 & 69.04 \\
Profession & single & 25 & 59.52 \\
& consensual union & 17 & 40.48 \\
& student & 36 & 85.71 \\
Household income (minimum wage) & from home & 5 & 11.9 \\
& paid activity & 23 & 54.76 \\
& $<1$ & 3 & 7.14 \\
Literacy & $1-2$ & 24 & 57.15 \\
& $>4$ & 3 & 7.14 \\
Cigarette use & Illiterate & 12 & 28.57 \\
Alcohol consumption & Elementary & - & - \\
Illicit drug use & high school & 5 & 13.88 \\
& college student & 30 & 83.33 \\
& Yes & 1 & 2.79 \\
& No & 11 & 26.19 \\
& Yes & 31 & 73.81
\end{tabular}

Socio-economic status was classified according to criteria from the Brazilian Association of Market Survey Institutes [31]. Thus, concerning economic class, $64.28 \%(n=27)$ of the participants belonged to classes $C$ and $D$, and $28.57 \%$ $(n=12)$ reported a monthly family income of up to four minimum wages. The main source of income came from the partner and/or parents.

Regarding social inclusion, the average number of years of school referred was eight years $(S D=2.86)$, ranging from 0 to 12 years. $21.43 \%$ of the adolescents $(n=9)$ were no lon- ger studying at the time of the interview; $55.55 \%$ $(n=5)$ associated dropout with pregnancy and $44.45 \%(n=4)$ had dropped out during the school year. $5(11.9 \%)$ adolescents reported having received some specific professional training. As for the total number of participants, $64.28 \%(n=27)$ said they were working. As shown in Figure 1, the number of adolescents who reported studying or entering the labor market varies according to the age considered. This number was always very low compared to the total of adolescents in each range. Overall, it is observed that, regardless of 
age, most adolescents did not study or work at the time of the interview.

Regarding habits and/or drug use during pregnancy, 11 adolescents (26.19\%) reported smoking on 7 cigarettes per day $(\mathrm{SD}=4.51)$, ranging from 5 to 45 cigarettes/day. About alcohol intake, 16 adolescents (38.09\%) admitted to drinking at least one occasion during pregnancy, and $8(19.05 \%)$ reported having consumed alcohol in an abusive way in all pregnancy. About other types of drugs (marijuana, cocaine, crack), $12(28.57 \%)$ admitted having used them during pregnancy, and $3(7.14 \%)$ of these reported injecting drug use. It was found that 7 adolescents $(16.66 \%)$ had a relationship with an injecting drug user partner.

As to sexual behavior, the average age of onset of sexual activity was 15.5 years $(S D=3.65)$, ranging from 13 to 18 years. Considering age at first birth, the average difference between the onset of sexual activity and childbirth was 4.0 years $(S D=3.98)$, ranging from 0 (childbirth in the same year of sexual activity) to five years. The average age of the partner was 22.92 years $(S D=11.04)$, ranging from 16 to 31 years. The average age difference between the adolescent and her partner was 7.42 years $(S D=8.45)$ ranging from minus 2 (younger partner) to 13 years.

The average age of the oldest child was 2.5 years $(S D=3.68)$, ranging from 1 to 4 years. In 14 cases $(33.33 \%)$, these children lived with their mother; in 27 cases $(64.28 \%)$ lived with close relatives, and one case $(2.39 \%)$ was placed for adoption.

About characteristics presented during pregnancy at the time of the interview, all were prenatal care in the hospital unit where the interview took place. For $90.47 \%(n=38)$ pregnancy was not planned, however for $57.14 \%(n=27)$ it was not considered convenient; finally, only $16.66 \%(n=6)$ used some contraceptive method when they became pregnant. 5 adolescents $(11.9 \%)$ thought about terminating the pregnancy, and 9 adolescents (21.43\%) attempted abortion, the vast majority referring to the use abortion drugs acquired through illegal means, but only 4 adolescents $(9.52 \%)$ had abortion (three spontaneous and one provoked).

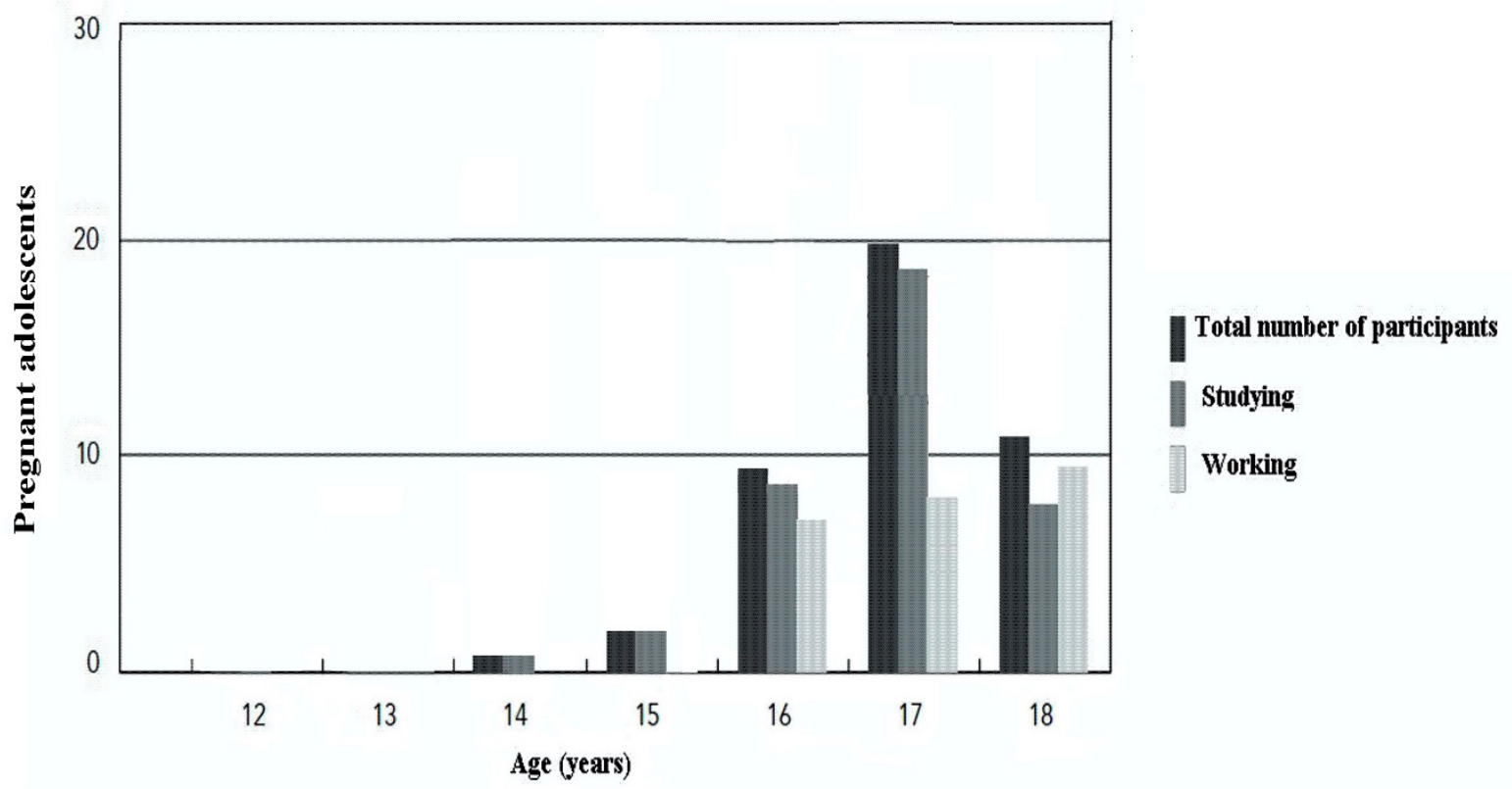

Figure 1. Social insertion of pregnant adolescents according to age. 


\section{DISCUSSION}

Adolescent pregnancy is a public health problem both in Brazil and in many other countries in the world. To understand the possible etiological factors related to the increase of pregnancies in this age group, it is necessary to understand the complexity and multicausality of these factors, making adolescents especially vulnerable to this situation. Protective factors are necessary for both mother and baby [32]. Thus, pregnancy is an ideal window of opportunity for intervention [33]. This opportunistic time offers to support women in making positive decisions about their own and their infant's wellbeing. Eizirik \& Bergmann [34] suggest a significant protective factor against the risk of harm to the babies when mothers are emotionally and socially connected to their families.

As shown in Figure 2, in 2017, a total of 194,377 babies were born to women aged 1519 years, for a birth rate of 18.8 per 1,000 women in this age group. Still, the U.S. teen pregnancy rate is substantially higher than in other western industrialized nations [35], and racial/ ethnic and geographic disparities in teen birth rates persist [36].

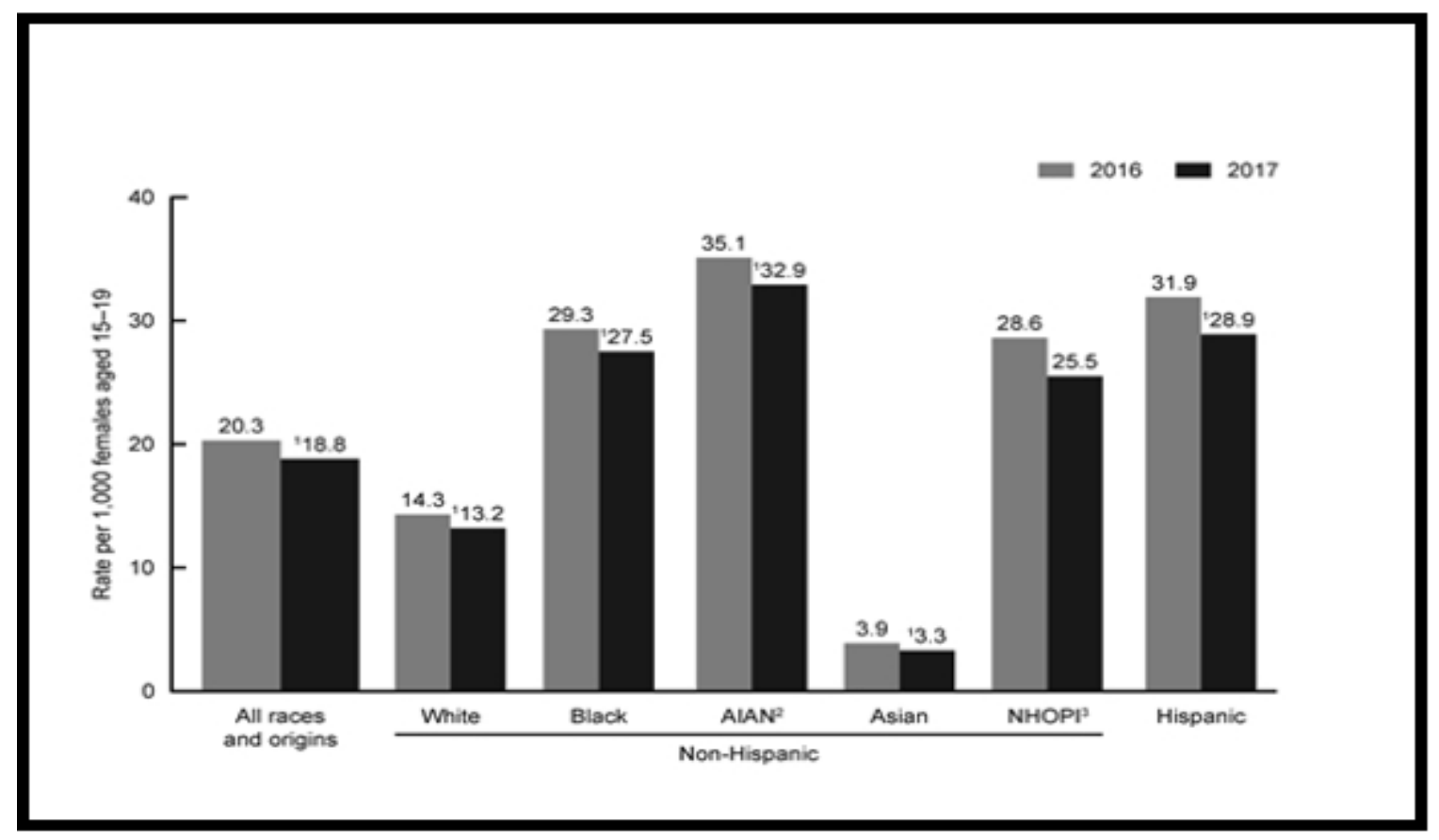

${ }^{1}$ Significant decline from $2016(p<0.05) ;{ }^{2} \mathrm{AIAN}=$ American Indian or Alaska Native; ${ }^{3} \mathrm{NHOPI}=$ Native Hawaiian or another Pacific islander; Source: NCHS. National vital Statistics System, Natality. CDC, USA, 2019.

Figure 2. Birth rates for females aged 15-19, by race and Hispanic origin of mother: United States, 2016 and 2017.

According to Buendgens \& Zampieri [37], society as a whole perceives pregnancy as a social problem, the result of social and family disruption, appeals related to sexuality in the media and idleness due to the lack of leisure spaces, consequences of dropping out of school, diminishing opportunities, increasing poverty and sometimes abandonment by family, friends, and peers, which may lead to attempted abortion. This fact is confirmed by studies on the perception of teenage pregnancy, which indicate that the influence of the media that trivialize sex contributes to teenage pregnancy and the fact that adolescents seek sex to fill their free time since they are not offered any other possibilities for fun $[25,38]$. Besides, they also cite the lack of family support and the economic and sociocultural issue, reinforcing that the adolescent is a biopsychological being and a being resulting from social and cultural issues.

Adolescent pregnancy needs to be discussed by health professionals and society, both in 
terms of care and planning, to understand the adolescent's experience and the care provided, as it is a public health problem [39].

\section{Risk behaviors - substance use}

Consumption of illicit drugs (marijuana, cocaine, ecstasy, amphetamines, crack, etc.) is a highly specific type of substance misuse that unfortunately has become usual during adolescence [40]. About $30 \%$ of the interviewees declared to use these substances. This result is more than 4 times higher than the prevalence of people aged 12 to 17 years who consumed any illicit substance in their life reported in the III National Survey on Drug Use by the Brazilian Population of 2015 , namely $4 \%$, with a lower limit (LL) of $2.4 \%$ and upper limit (UL) of $5.7 \%$. If the comparison is made with the prevalence of consumption of this same age group in the last 12 months and the last 30 days, the difference with the findings of this study is even greater, since the III survey recorded $2.3 \%$, respectively (1.0 LL and $3.6 \mathrm{UL}$ ) and $1.3 \%$ (0.3 LL and $2.4 \mathrm{UL}$ ) [41].

However, it is necessary to emphasize that the data collected in this research come from self-declaration and illicit drug misuse is routinely associated with criminal behavior, which logically places those who misuse illicit drugs within the same context [42]. Thus, this percentage of $28.57 \%$ of pregnant adolescent drug users could be even higher. Therefore, special effort is needed to develop effective preventive campaigns against illicit drug misuse in adolescents. One of the possible approaches is the identification of the precipitating factors [43], which will allow targeting of those adolescents who are at specific risk for illicit drug misuse and consequently will assure the development of accurate and specifically tailored preventive programs, also avoiding pregnancy in adolescents and the risks involved.

The number of pregnant adolescents who use illicit drugs is not well known despite increased awareness that drug misuse and abuse impact maternal and child wellbeing. Surveys undertaken in New South Wales (NSW), the Australian Capital Territory (ACT), and the National Household Drug Survey 2016 on populations aged 14 and over, suggest that up to $6 \%$ of all pregnancies are affected by illicit drug use [44].

Regarding alcohol, about $40 \%$ of the interviewees declared to be consumers. This result is compatible with the use of alcoholic beverages also reported in this III survey of 2015 . The prevalence of consumption of people between 12 and 17 years of age is $34.3 \%$ (30.6\% LL and $38.0 \%$ UL) [41]. This means that the behavior of pregnant adolescents concerning alcohol observed in this research did not differ significantly from that of other Brazilian adolescents.

As for cigarette use, the prevalence among pregnant adolescents of $26.19 \%$ in this research was higher than that found about people aged 12 to 17 years in this III survey of 2015. The prevalence of cigarette consumption in this age group varies from $6.3 \%(4.2 \% \mathrm{LL}$ and $8.3 \% \mathrm{UL})$ of lifetime consumption, $3.8 \%(2.2 \% \mathrm{LL}$ and $5.4 \% \mathrm{UL})$ in the last 12 months and $2.4 \%(1.2 \% \mathrm{LL}$ and $3.5 \%$ $\mathrm{UL})$ in the last 30 days [41].

\section{Socioeconomic risks}

Most adolescent mothers were primiparous, but $9(21.43 \%)$ of those who had previously had children was higher than that found by Rocha-Aguiar et al. [45]. Other studies have found that recurrence of pregnancy is influenced by a variety of causes, such as early menarche and early onset of sexual life, school difficulties and subsequent dropout, low family income, lack of paid occupation, steady older partner, low use of condoms, family history of teenage pregnancy, absence of own father, family approval of previous pregnancy, previous abortion, well-regarded prior delivery by adolescent and absence of previous postpartum review $[43,46]$. These data are important because it showed that the experience of teenage pregnancy aggravates unfavorable living conditions, exposing women to a greater number of pregnancies and abortions, to smoking and illicit drugs [38].

An important aspect of the findings of the present study is related to the educational level of the adolescents' parents, which seems to influence the use of contraceptive methods among the interviewed adolescents. Adolescents with 
higher socioeconomic status had significantly higher knowledge of contraceptive methods, indicating that the most privileged classes would have greater access and contact with the most efficient means of information.

The knowledge, attitude, and practice related to contraceptive methods observed in the present study showed significant advances in the information available and appropriate by adolescents. However, the availability of knowledge, services, and methods to favor adolescents' change of attitude towards an efficient and preventive use practice does not seem to have been enough. Therefore, there is a need to seek new ways of acting with the adolescent population, since pregnancy in this phase is a public health problem, and consequently a risk for morbidities.

As the profile data of adolescent mothers and their births and risk factors for teenage pregnancy were mainly related to unfavorable socioeconomic conditions, the necessary intervention requires intersectoral actions. There must be a joint effort from various sectors of society to meet the needs of young people. The health sector must organize its services in a different way for the reception and monitoring of adolescent health, with a motivated and qualified multidisciplinary team to work with people of this age group. Partnerships with governmental and non-governmental social education and promotion institutions, families, and the community are also important so that, through information, knowledge, protection, and support, young people can move into adulthood in a healthy and responsible way.

\section{Prenatal care as a factor in reducing mater- nal and child health risks}

Related to prenatal attendance, it was found that more than one-third of adolescents attended less than seven prenatal consultations, unlike most adults who attended the appropriate number of appointments recommended by Attention to Women's Health. These findings are consistent with other studies that linked teenage pregnancy with poor prenatal adherence $[47,48]$.

Research demonstrates that maternal-child health outcomes are enhanced exponen- tially if were accessed prenatal care throughout pregnancy [49]. Prenatal care provides the opportunity for service providers to offer health education, prevention, and intervention designed to promote positive obstetric and pediatric outcomes. Pregnant adolescents who use illicit drugs and present for antenatal care are directed to services to minimize harm from drug use to themselves and the growing fetus. Although pregnant adolescents who use illicit drugs present late for health care, this is the time when they become visible to maternity services $[50,51]$. WHO [52] supports the recommended guidelines for the management of drug use during pregnancy, (detaching also adolescent pregnancy) birth and the early development years of the new-born as a useful manual for midwifery and other health professionals practice.

\section{CONCLUSIONS}

The challenges to development faced by youth as they try to attain the knowledge and skills requisite for success in society are many of the same ones adolescents face in trying to build successful personal, family, and community lives. Their resources and the social contexts they find themselves hold the key to both positive and negative developmental changes.

According to the findings and the conclusion; these pregnant adolescents at such an early age need an early identification of these new addiction problems and in that sense it is recommended: (i) Promote research studies to identify the protective factors of pregnant adolescents in these situations of social, economic crisis and values; (ii) To deepen and expand the study on the concepts of Health, Education, Values and Life Projects of adolescents in a Globalized society; (iii) Analyze the programs of Reproductive Health regarding responsibility of the state, institution and family; (iv) Analyze the coverage of material resources and personal capacities for the attention of a population informed; ( $v$ ) Establish in the prenatal control a special Items for the pregnant adolescent where specified Addiction risks and other pathologies of this stage and situation; (vi) Strengthen and promote special 
attention in prenatal control offices to plan care in the pre and post-consultation of the adolescent pregnant; and (vii) empower and train the maternal team to identify the resilience factors of an adolescent girl in risk of drug consumption, in order to carry out a personalized care plan and its appropriate referral.

\section{REFERENCES}

1. Oliveira-Campos M., Nunes M.L., Madeira F.C., Santos M.G., Bregmann S.R., Malta D.C., Giatti L., Barreto S.M., 2014. Sexual behavior among Brazilian adolescents, National Adolescent School-based Health Survey (PeNSE 2012). Revista Brasileira de Epidemiologia. 17(Suppl. 1), 116-130.

2. Kanwetuu V.P., Mokulogo R.K., Azumah F.D., 2018. Understanding adolescents' sexual behavior in Ghana: Information sources and their effects. Journal of Sexuality and Culture. 22(3), 942-961.

3. Osaki H., Mshana G., Mbata D., Kapiga S., Changalucha J., 2018. Social space and alcohol use initiation among youth in northern Tanzania. PLoS One. 13(9),1-14.

4. Santos M.A., \&Pratta E.M.M., 2012. Adolescência e uso de drogas à luz da psicanálise: sofrimento e êxtase na passagem. Tempo psicanalítico. 44(1), 167-182.

5. Santos A.R., Perrelli J.G.A., Silva T.T.M., Lopes M.V.O., Frazão I.S., 2018. Instrumentos relacionados ao consumo de drogas em adolescentes: revisão integrativa. Texto \& Contexto - Enfermagem. 27(3), e0370017.

6. Salvador J., Ryan J.S.B., Alvarez M.O., Rosario A., 2016. The phenomenon of teenage pregnancy in the Philippines. European Scientific Journal. 12, 173-192.

7. Hoffmann J.P., 2017. Family structure and adolescent substance use: an international perspective. Substance Use \& Misuse. 52(13), 1667-1684.

8. Silverman J.G., Raj A., Mucci L.A., Hathaway J.E., 2001. Dating violence against adolescent girls and associated substance use, unhealthy weight control, sexual risk behavior, pregnancy, and suicidality. JAMA. 286(5), 572579.

9. Chapman S.L.C., Wu L.T., 2013. Substance use among adolescent mothers: A review. Children and Youth Services Review. 35(5), 806-815.

10. Ferreira A.P., 2019.Estimaciones del consumo de drogas ilícitas derivadas del análisis de aguas residuales: Una revisión crítica. RevUnivInd Santander Salud. 51(1), 6980.

11. Leve L., Chamberlain P., Kim H., 2015. Risks, outcomes, and evidence-based interventions for girls in the US juvenile justice system. Clinical Child \& Family Psychology Review. 18(3), 252-280.
12. Respress B.N., Amutah-Onukagha N.N., Opara I., 2018. The effects of school-based discrimination on adolescents of color sexual health outcomes: a social determinants approach. Social Work in Public Health. 33(1), 1-17.

13. Aparicio E.M., Phillips D.R., Okimoto T., Cabral M.K., Houser C., Anderson K., 2018. Youth and provider perspectives of Wahine Talk: A holistic sexual health and pregnancy prevention program developed with and for homeless youth. Children and Youth Services Review. 93, 467-473.

14. Tuitt N., Asdigian N., Kaufman C., 2019. Frequent residential mobility among American Indians and early indications of sexual risk among young adolescents. PLoS One. 14(6), p.e0218445.

15. Watkins-Kagebein J., Barnett T., Collier-Tenison S., Blakey J., 2019. They don't listen: A qualitative interpretive meta-synthesis of children's sexual abuse. Child \& Adolescent Social Work Journal. 36(4), 337-349.

16. Salas-Wright C.P., Vaughn M.G., Ugalde J., Todic J., 2015. Substance use and teen pregnancy in the United States: Evidence from the NSDUH 2002-2012. Addictive Behaviors. 45, 218-225.

17. Sentino P., Thompson P.L., Nugent W.R., Freeman D. 2018. Adolescent daughters' perceptions of their fathers' levels of communication and care: How these variables influence female adolescent sexual behaviors. Journal of Human Behavior in the Social Environment. 28(5), p.632-646.

18. Okumu M., Ombayo B., Small E., Ansong D., 2019. Psychosocial syndemics and sexual risk practices among U.S. adolescents: findings from the 2017 U.S. youth behavioral survey. International Journal of Behavioral Medicine. 26(3), 297-305.

19. Richard J., Potenza M., Ivoska W., Derevensky J., 2019. The stimulating nature of gambling behaviors: relationships between stimulant use and gambling among Adolescents. J Gambl Stud. 35(1), 47-62.

20. Whitton S.W., Dyar C., Newcomb M.E., Mustanski B., 2018. Effects of romantic involvement on substance use among young sexual and gender minorities. Drug and Alcohol Dependence. 191, 215-222.

21. Saldanha K., Madangopal D., 2019. The social dimensions of gambling among street youth in Mumbai: Is it really an addiction? Qualitative Social Work. 18(2), 265285.

22. De Genna N.M., Cornelius M.D., Donovan J.E., 2009. Risk factors for young adult substance use among women who were teenage mothers. Addictive Behaviors. 34(5), 463-470.

23. Azomahou T., Diagne A., Pape Y., Kaba I., 2019. Public finances and tobacco taxation with product variety: Theory and application to Senegal and Nigeria. PLoS One. 14(2), p.e0212015.

24. Coleman-Cowger V.H., Schauer G.L., Peters E.N., 2017. Corrigendum to "Marijuana and tobacco co-use among 
a nationally representative sample of US pregnant and non-pregnant women: 2005-2014 National survey on drug use and health findings". Drug Alcohol Depend. $177,130-135$.

25. Copeland R.J., 2017. Experiences of adolescent mothers in Costa Rica and the role of parental support. Journal of Family Social Work. 20(5), 416-433.

26. Hagstrom P., Wu S., 2016. Are pregnant women happier? Racial and ethnic differences in the relationship between pregnancy and life satisfaction in the United States. Review of Economics of the Household. 14(3), 507-527.

27. Anderson S.A., Sabatelli R.M., Trachtenberg J., 2007. Community police and youth programs as a context for positive youth development. Police Quarterly. 10(23), $23-40$.

28. Jimmyns C., Meyer-Weitz A., 2019. The Influence of School Contextual Factors on Educators' Efforts in Teaching Sexuality Education in Secondary Schools in Durban, South Africa. Sexuality \& Culture. 23, 1110-1130.

29. Pinheiro S.N., Laprega M.R., Furtado E.F., 2005. Morbidade psiquiátrica e uso de álcool em gestantes usuárias do Sistema Único de Saúde. Revista de Saúde Pública. 39(4), 593-598.

30. Koletic G., Kohut T., Stulhofer A., 2019. Associations between adolescents' use of sexually explicit material and risky sexual behavior: A longitudinal assessment. PLoS One. 14(6), p.e0218962.

31. Associação Nacional de Empresas de Pesquisa. Critério de classificação econômica Brasil. http://www.abep.org/ criterio-brasil Accessed July 5, 2019). (Accessed July 5, 2019).

32. Vanderbilt-Adriance E., Shaw D.S., 2008. Protective factors and the development of resilience in the context of neighborhood disadvantage. Journal of Abnormal Child Psychology. 36(6), 887-901.

33. Arabin B., Baschatt A.A., 2017. Pregnancy: An underutilized window of opportunity to improve long-term maternal and infant health - An appeal for continuous family care and interdisciplinary communication. Frontiers in Pediatrics. 5. 69. 10.3389/fped.2017.00069.

34. Eizirik M., Bergmann D.S., 2004. Father absence and its influence on child and adolescent development: a case report. Revista de Psiquiatria do Rio Grande do Sul. 26(3), 330-336.

35. Sedgh G., Finer L.B., Bankole A., Eilers M.A., Singh S., 2015. Adolescent pregnancy, birth, and abortion rates across countries: levels and recent trends. Journal of Adolescent Health. 56(2), 223-230.

36. Romero L., Pazol K., Warner L., Cox S., Kroelinger C., Besera G., Brittain A., Fuller T.R., Koumans E., Barfield W., 2016. Reduced disparities in birth rates among teens aged 15-19 years - United States, 2006-2007 and 20132014. Morbidity and Mortality Weekly Report. 65(16), 409-414.

37. Buendgens B.B., Zampieri M.F.M., 2012. The pregnancy in adolescence on the perception of doctors and nurses from a primary care. Escola Anna Nery Revista de Enfermagem. 16(1), 64-72.

38. Ferrari W., Peres S., Nascimento M., 2018. Experiment and learning in the affective and sexual life of young women from a favela in Rio de Janeiro, Brazil, with experience of clandestine abortion. Ciência\&SaúdeColetiva. 23(9), 2937-2950.

39. Pereira M.O., Sá M.C., Miranda L., 2017. A wave that comes rushing in and dunks you: representations and destinies of the crisis in adolescent users of a CAPSi. Ciência\&SaúdeColetiva. 22(11), 3733-3742.

40. Degenhardt L., Whiteford H., Hall W., Vos T., 2009. Estimating the burden of disease attributable to illicit drug use and mental disorders: what is 'Global Burden of Disease 2005' and why does it matter? Addiction. 104(9), 1466-1471.

41. Bastos FIPM et al. (Org.). III Levantamento Nacional sobre o uso de drogas pela população brasileira. Rio de Janeiro: FIOCRUZ/ICICT, 2017.

42. Green K.M., Doherty E.E., Stuart E.A., Ensminger M.E., 2010. Does heavy adolescent marijuana use lead to criminal involvement in adulthood? Evidence from a multiwave longitudinal study of urban African Americans. Drug and Alcohol Dependence. 112, 117-125.

43. Gindri Resta D., Santos Colomé I.C., Bernadete Trovó de Marqui A., ZielkeHesler L., Eisen C., 2014. Adolescents: for what reasons do they get pregnant? Revista de Enfermagem UFPE. 8(5), 1229-1236.

44. Chalmers J., Lancaster K., Hughes C., 2014. The stigmatization of 'ice' and under-reporting of meth/amphetamine use in general population surveys: a case study from Australia. International Journal of Drug Policy. 36, 15-24.

45. Rocha Aguiar F.A., Lira Dourado J.V., Alexandre de Paula P.H., Souto Pinto Menezes R., Camelo Lima T., 2018. Experience of pregnancy among pregnant teenagers. Revista de Enfermagem UFPE. 12(7), 1986-1996.

46. Villarán Landolt V., Traverso Koroleff P., Huasasquiche Vinces M.L., 2017. Narrativas sobre el embarazo y la maternidad en mujeres adolescentes de sectores urbano marginales de Lima que acaban de dar a luz. Psicología. 35(2), 485-508.

47. Brito M.B., Alves F.S.S., Souza M.Q., Requião S.R., 2018. Low level of knowledge of contraceptive methods among pregnant teens in Brazil. Journal of Pediatric and Adolescent Gynecology. 31(3), 281-284.

48. Katz J., Gravelin C., O'Brien C., 2018. Neoliberal beliefs and perceptions of unintended adolescent pregnancy after consensual or forced sex. Sex Roles. 78(11), 810821.

49. Mahajan H., Sharma B., 2014. Utilization of maternal and child health care services by primigravida females in urban and rural areas of India. ISRN Preventive Medicine. 123918.

50. Mansur A.M., Rezaul K.M., Mahmudul H.M., 2014. Quality of antenatal care in primary health care centers of 
Bangladesh. Journal of Family and Reproductive Health. $8(4), 175-181$.

51. Roberts S., Pies C., 2011. Complex calculations: how drug use during pregnancy becomes a barrier to prenatal care. Maternal and Child Health Journal. 15:333.
52. World Health Organization. Guidelines for the Identification and Management of Substance Use and Substance Use Disorders in Pregnancy. Geneva: World Health Organization; 2014. Recommendations. https://www. ncbi.nlm.nih.gov/books/NBK200683/. Accessed: July 5, 2019.

\section{Acknowledgments}

This study was financially supported by National Council for Scientific and Technological Development (CNPq).

\section{Conflicts of interest}

The author declares no conflicts of interest.

\section{Ethical consideration}

The present work had the approval of the Research Ethics Committee of the Sergio Arouca National School of Public Health (ENSP/FIOCRUZ).

Autor Correspondente:

Cíntia da Silva Telles Nichele

cintiatelles.ensp@gmail.com

Editor:

Prof. Dr. Marcelo Riberto

Received in: aug 23, 2020

Approved in: dec 04, 2020 